\title{
The natural approach to adult learning and teaching of L2 grammar
}

\author{
PAWE $Ł$ SCHEFFLER
}

\begin{abstract}
Learning a language in a natural way is normally understood to involve the development of implicit knowledge of that language. The acquisition of such knowledge takes place through communication and is driven by learnerinternal mechanisms which cannot be directly influenced by formal instruction. In the case of foreign or second language (L2) learning, the role of instruction is, then, to provide learners with opportunities for communication, and with assistance in those areas in which implicit learning is impossible or inefficient.

This article argues that in the case of adult L2 learners the term "natural learning" should be interpreted as referring to explicit learning. This means that adult $L 2$ instruction should primarily aim to engage the learners' problemsolving mechanism by providing them with explicit rules about the target code, and then with opportunities for proceduralizing and automatizing those rules. L2 acquisition is thus treated as the acquisition of a complex skill.
\end{abstract}

\section{Teaching through tasks}

\subsection{Basic assumptions}

To most people the traditional way of learning a foreign or second language ${ }^{1}$ probably means being involved in formal instruction of some sort. The instruction normally takes place in the classroom setting and mostly consists of studying various linguistic features of the target language. However, as Krashen and Terrell (1983: 7) point out, this view of traditional L2 learning does not reflect the way in which languages have traditionally or normally been acquired by

1. The term "foreign language" will be used to refer to a language that is learnt in a country where it is not spoken as the native language of the society. If learning takes place in a country where the target is spoken by the society, then the term "second language" will be employed. 
adult learners ${ }^{2}$ over the centuries. They say that the traditional or normal L2 acquisition necessarily involves using language for communication, and that being exposed to comprehensible L2 input triggers natural acquisition processes. These processes lead to the development of subconscious linguistic competence, which underlies all spontaneous L2 production. The role of conscious learning is minimal: the knowledge accumulated in this way can only be used to edit or monitor performance provided a number of conditions are met. There is no interface between explicit and implicit knowledge in this system: the former can in no way contribute to the development of the latter.

The view that participating in communicative exchanges in a target language is crucial for language development has also been expressed by other SLA specialists, for example Pica (1994), Long (1996), Willis (1996), Long and Robinson (1998), Ellis (2003) and Nunan (2004). For the researchers just mentioned, there are three principle ways in which interaction between learners and other speakers can contribute to the acquisition of implicit linguistic knowledge. First, it can provide learners with comprehensible input. Second, it can enable them to elicit negative evidence. Third, it can push them to modify their output. What this means for L2 instruction is that it should be organized in such a way that learners are given opportunities to interact freely with the teacher and other learners. One of the ways in which this can be achieved is through the use of tasks.

Advocates of the task-based approach reject structural syllabuses as a viable means of developing L2 proficiency. Long and Robinson (1998) point out a number of features of structural syllabuses which they see as serious flaws. For example, materials designed along structural lines present language acquisition as a process of accumulating independent, distinct entities. Also, the acquisition of particular entities or rules is supposed to be a process of sudden categorical change. But, as Long and Robinson (1998: 17) state, "morphosyntactic development involves prolonged periods of form-function mapping", which means that learners do not move instantly from the state of not knowing a rule to a mastery of that rule.

Further, imposing a particular sequence of linguistic elements on the learner disregards research findings which indicate that in the process of L2 acquisition learners follow "fixed developmental sequences" in certain grammatical areas (for example word order, negation, interrogatives) and acquire a number of grammatical morphemes in a fixed order. The existence of such patterns indicates that learners appear to follow an internal syllabus and that attempts to interfere with it are not likely to be successful. In the view of Long and

2. In this paper, the term "adult learner" will refer to a learner whose cognitive development has reached the stage of formal operations, as described in the theory of Jean Piaget (e.g. Inhelder and Piaget 1958). 
Robinson, traditional approaches to foreign language teaching often fail precisely because they do not respect these internal processes in the learner. Citing as evidence "the ratio of beginners and false beginners to finishers", and the widespread use of traditional teaching methods all over the world, Long and Robinson (1998: 20) say that phenomena like

grammatical syllabi, linguistically "simplified" teaching materials, explicit grammar explanations, immediate forced student production, pattern practice, translation, error "correction"

should be associated with failure, and that it is more likely that those who succeed do so "in spite of them" rather than "because of them".

The rejection of a structural syllabus and the adoption of a task as a unit of the syllabus organization does not necessarily mean that attention to formal features of the target language is viewed as irrelevant to the process of instruction. For Long and Robinson (1998) attention to form is supposed make the learning process more efficient and enable adult learners to acquire those target features which cannot be picked up from comprehensible input or interactional exchanges.

Focus on form can be implemented both implicitly and explicitly. An example of an implicit technique is recasting, that is, providing learners with corrective reformulations of their utterances. Negative evidence can also be given to learners in an explicit manner: Long and Robinson (1998) allow for the teacher's intervention consisting in briefly interrupting a group activity to deal with particularly persistent errors.

Summing up, one can say that the "naturalness" of task-based instruction (TBI) rests on two main factors. First, it attempts to develop in learners implicit linguistic knowledge by engaging them in "the kinds of cognitive processes that arise in communication outside the classroom" (Ellis 2003: 336). Second, by rejecting a pre-determined grammatical syllabus and relying on incidental focus on form, task-based instruction is supposed to enable each learner to receive feedback relevant to his or her stage of development, thus respecting the natural sequences of development (Skehan 2002).

\subsection{Problems with basic assumptions}

1.2.1. Learning from interaction. The task-based approach sketched above combines meaning-based activities with incidental focus on form. It rests on the assumptions that communicative interaction can drive language acquisition forward and that this kind of interaction can be successfully achieved in the classroom. As a matter of fact, both of these assumptions are questionable. 
Skehan and Foster (2001), Bruton (2002) and Swan (2005) point out that there is little empirical evidence for postulating a link between interaction and acquisition. The vast majority of research into task-based instruction has been concerned with determining when negotiation of meaning occurs rather than with attempting to provide empirical substantiation of the connection between such negotiation and acquisition.

The need for empirical evidence is made particularly strong because in the task-based approach, as in all analytic approaches, it is the learner that is responsible for analysing the code and breaking it up into any grammatical rules underlying it. The problem with expecting the learner to perform this kind of syntactic analysis is that in speech comprehension and production no detailed syntactic analysis is normally necessary. It has often been pointed out (e.g. Widdowson 1990; Skehan 1998; Skehan and Foster 2001) that in decoding meaning learners are likely to draw on their schematic and contextual knowledge, and that in the encoding process various communicative strategies are likely to be employed. Even if a breakdown in communication occurs, and this triggers negotiation of meaning, it is lexis rather than syntax that is more likely to be negotiated, the main reason for this being the communicative redundancy of many of the morphosyntactic features of the code. All this indicates that in an analytic approach probably the only reliable way in which the learner can be assisted in developing any kind of underlying grammatical competence is an intervention on the part of the teacher when an error occurs.

Even if it is ultimately demonstrated empirically that communicative interaction makes a significant contribution to acquisition, it is still not clear to what extent it can be used as an effective classroom procedure for inducing the negotiation of meaning and form by learners. While there are empirical studies (e.g., Gass and Varonis 1985, Doughty and Varela 1998, Ellis et al. 2001) which demonstrate that learners do make interactional adjustments when engaged in communicative exchanges, due to the experimental setting in which many of these studies were carried out, and due to the fact that many of them focused on teacher-learner interactions, their findings may not be generalisable to large secondary school EFL classrooms in which tasks are dominated by learner-learner interactions. A study by Foster (1998) shows that there is very little negotiation of meaning between the learners themselves (particularly in the area of grammar), even during tasks which are specifically designed to induce it. Foster suggests that the main reason for the unwillingness on the part of her learners to negotiate meaning was their adoption of the communicative strategy, which she describes as "pretend and hope". That is, instead of interrupting the flow of a communicative activity every time a learner was unclear about some aspect of the message, he or she elected to ignore the problem, hoping that the following utterances would clear the matter up. Adopting this strategy enabled the learners to avoid the frustration and discouragement which 
might result from numerous attempts to clarify cases of non-understanding. Foster concludes that if we want to push learners to attend to formal linguistic features, we will be better off pursuing an approach along the lines of Swain (1995), which, in general, consists of first getting learners to produce the target language and then getting them to consciously reflect on its structure. This, however, means that we leave the realm of "focus on form" and enter the territory of "forms".

1.2.2. "Traditional approaches have failed". As has already been mentioned, one of the charges that Long and Robinson (1998) level at focus on forms and structural syllabuses is that most learners subjected to this kind of instruction fail to become L2 "finishers". Swan (2005: 386-387), who in general argues against the rejection of code-focused teaching, also says that traditional methods "have not done very well" and talks about a "sense of failure" associated with them.

It seems to me that one can talk about failure (in different degrees) as characteristic of adult L2 development, but only when success is measured by reaching (near) native-like mastery of the target language, which is what Long and Robinson imply by the term "finishers." There are two reasons why it is reasonable to suggest that this is not necessarily the right criterion for evaluating learners' achievement.

The first has to do with the kinds of goals that learners set. As is the case with acquiring other cognitive skills, perfect mastery need not be the target of the learning process: for some L2 learners success might mean acquiring basic communication skills in order to get by while travelling in the country where the target language is spoken. This means that in L2 learning, as in learning other skills, success should be gauged by the degree to which learners achieve the goals that they themselves set. My view, then, is that when describing achievement in L2 learning it is more appropriate to talk about different degrees of success than about different degrees of failure.

The second reason why I would argue that it is not necessary to equate success in adult L2 acquisition with near native-like or even advanced competence, relates to the following two factors: the enormous complexity of the system that needs to be mastered and the conditions under which this task is to be accomplished. The fact that the system is complex need not be elaborated on here: it is evident from any discussion of linguistic phenomena in the relevant literature. What has to be stressed is that an adult learner needs to master this very complex system under various constraints. These external and internal constraints relate, inter alia, to the time that a learner can devote to the process of learning, the amount of exposure that he or she gets, the quality of teaching that he or she receives, the level of motivation that is present and the strength of the affective 
barriers that need to be overcome. ${ }^{3}$ Given the number and scale of the potential problems facing the learner, the definition of what counts as success in foreign language acquisition could perhaps be a little less restrictive than is often proposed. For the same reason Long and Robinson's (1998) claim that traditional linguistically-driven instructional devices equal failure and that these devices are responsible for so many beginners failing to become "finishers" seems to me unwarranted.

The view that structural syllabuses produce unsuccessful language learners is also questioned by Sheen (1994: 142-143), who makes the following comment:

... perhaps some of the most successful language learners are produced in European countries such as Denmark, Holland and Germany where deductive approaches (i.e., the most synthetic of synthetic syllabuses) still characterize mainstream teaching of English as they have done for decades ... ${ }^{4}$

Sheen's assertion is of course weakened by the fact that the mother tongues of Danish, Dutch and German learners are related and similar to the target. Still, it is certainly true that, regardless of their L1 background, "countless people seem to have learnt languages over the centuries through the kind of instruction currently condemned in the TBI literature" (Swan 2005: 386). If Long and Robinson were correct, all those successful learners would have to overcome the obstacles posed by the structural syllabus, and, somehow, use the input they were provided with to subconsciously create L2 linguistic competence. This scenario seems, however, very unlikely.

Evidence for the effectiveness of explicit instruction also comes from empirical research. Over the past few decades there have been numerous empirical studies of the effectiveness of various types of instruction. Norris and Ortega (2000) provide a statistical meta-analysis of the research carried out between 1980 and 1998. They reach several important conclusions, three of which are relevant to the present discussion. Firstly, when compared with simple exposure, L2 instruction is effective and makes a substantial difference. Secondly,

3. In discussing the ineffectiveness of traditional approaches Swan (2005: 387) also stresses factors like "poor teaching, unsuitable materials, or unsatisfactory syllabus design".

4. Sheen's remarks about the dominant position of the structural syllabus describe the situation in the early 1990s. Since then, as Nunan (2004) points out, task-based instruction has evolved from a research project pursued by SLA specialists to one of the central principles which educational institutions claim they use in designing their English language curricula. However, Nunan also observes that there is likely to be a large gap between these official pronouncements and the reality of the classroom, in which the structural approach is still frequently followed. 
explicit types of instruction are superior to implicit ones in terms of effectiveness. Thirdly, the effects of L2 instruction seem to last beyond immediate post-experimental observations.

When interpreting these findings, one needs to keep in mind what Norris and Ortega (2000: 486) say about the outcome measures that were typically used to assess effectiveness: "[g]enerally, the observed instructional effectiveness within primary research to date has been based much more on the application of explicit declarative knowledge under controlled conditions, without much requirement for fluent spontaneous speech." This means that if one wants to ascribe communicative value to L2 explicit/declarative knowledge, one needs to show how this knowledge can ultimately lead to spontaneous L2 performance.

1.2.3. Fixed developmental patterns. A number of studies in the 1970s and 80 s demonstrated that both child and adult L2 English learners from various L1 backgrounds acquire certain grammatical morphemes or functors in a fixed order. As has already been mentioned, the existence of such orders is seen by proponents of TBI as evidence against the feasibility of pre-planned grammar instruction and structural syllabuses: if L2 learners follow some built-in syllabus, then it seems to make little sense to impose an external syllabus on them. I would like to argue, however, that the existence of acquisitional orders does not justify a move towards task-oriented teaching.

First of all, it needs to be pointed out that L2 instruction can be directed at the development of two distinct types of knowledge: explicit and implicit (e.g., Hulstijn 2005). If the development of the former is based on a general (rather than specifically linguistic) cognitive mechanism, then one should not expect this mechanism to impose any rigid constraints on the order in which particular items are acquired. This indeed seems to be the case: Ellis (1994: 635) says that research into developmental patterns has concerned implicit knowledge and that " $[\mathrm{t}]$ here is no evidence that explicit knowledge of grammatical rules is acquired in some fixed order or sequence." Thus, for instruction concerned with explicit knowledge, the question of fixed developmental sequences is irrelevant.

As for implicit knowledge, Swan (2005) points out that the existence of acquisition orders should render both pre-planned and incidental teaching of formal features equally pointless. The reason for this is that noticing, and readiness for, acquisition are two different things: learners may notice their inability to express a particular meaning without being able to acquire the relevant structure. This means that regardless of whether pedagogic treatments are preplanned or incidental, there is no guarantee that the learners to whom they are addressed have reached an appropriate level of development. 
The conclusion that all formal instruction directed at implicit knowledge is basically a hit-or-miss affair is based on the assumptions that the orders obtained are correct and that they are inviolable. However, the morpheme studies and Krashen's Natural Order Hypothesis based on them have been severely criticized on both theoretical and empirical grounds (e.g., Gregg 1984, Rosansky 1976). Also, there is empirical evidence that indicates that acquisition orders might be subverted. In a meta-analysis of the research into the order of acquisition of grammatical functors by learners of L2 English, Goldschneider and DeKeyser (2001) demonstrate that five determinants account for a large percentage of the total variance in L2 English functor acquisition: perceptual salience, semantic complexity, morphological regularity, syntactic category and frequency. Furthermore, these five determinants are not a heterogeneous set: they can be treated as five different aspects of salience (i.e., phonological, semantic, morphological, syntactic, and numerical respectively).

What this means is that in broad terms there is just one variable, salience, that is responsible for the phenomenon in question. It also means that there is no need to appeal to some "innate blueprint" to explain the predictability of the acquisition order: for the most part, the reason lies in the features of the acquired elements themselves. Finally, Goldschneider and DeKeyser's findings indicate that it might be possible for teachers or syllabus designers to accelerate the rate of acquisition of particular functors by increasing their salience.

Fixed developmental patterns are not restricted to morpheme orders. It is also well documented that in the acquisition of syntactic structures like negatives and relative clauses L2 learners of English pass through a number of developmental stages. This means that before a learner reaches the target norm, he or she produces transitional structures which differ from the norm: for example negative expressions with external negation and relatives with resumptive pronouns. In a review of the relevant literature, Ellis (1994: 100) says that as far as English negation is concerned, a learner may take more than two years to acquire all the relevant target rules, and "some never travel the whole distance."

As was the case with the morpheme acquisition order, the developmental patterns that have been discovered relate to implicit knowledge: again, no evidence exists that explicit knowledge is subject to developmental constraints like those of Pieneman (1985). As a matter of fact, there is now some evidence to the contrary: Spada and Lightbown (1999) show that formal instruction can enable learners to skip certain stages in a developmental sequence. They conclude that progress in L2 acquisition may depend on the type of instruction that is applied and not on the developmental constraints imposed on the learner. 


\subsection{Problems with implementing TBI}

1.3.1. Planning and accountability. According to Skehan (1998) there are three main reasons which explain the persistence of the traditional PPP format: secure teacher roles, secure teacher training, and clear accountability. Teachers are also partly to blame: they are described by Skehan (1998: 94) as "a conservative profession, out of touch with language acquisition studies". A mitigating factor is, as Skehan admits, the fact that they have not been provided with a clear pedagogic alternative. Skehan's (1998) framework for implementing task-based instruction is an attempt to remedy this situation.

Skehan is aware of the fact that teachers need some way of monitoring the development of their learners' interlanguage: they need to know what has been learnt and what still needs to be learnt. This is very easy in the PPP model: teachers follow a syllabus which contains the structures that are to be used and mastered by their learners. TBI is very different: it assumes a "non-deterministic" approach to structure, which means that the use of particular structures cannot be guaranteed. For this reason Skehan proposes that it is learners themselves that should be made responsible for monitoring their own progress. That is, from time to time each learner should take stock of his or her developing L2 system. Based on the learners' assessments, the teacher can then plan a range of structures for each individual task.

In my view, there are at least three reasons why Skehan's proposal is not feasible. First, as any secondary school teacher will testify, the average L2 learner is far from being an ideal, highly-motivated learner, prepared to take responsibility for the instruction process. If learners often have problems handing in their homework assignments on time, can they be left with a task on which the entire instruction process depends? Second, performing an assessment of one's developing L2 system requires a great deal of metalinguistic resources. Where is this metalinguisitc knowledge supposed to come from, if language is not treated in task-based instruction as an object of study? Finally, in large secondary school classes there are bound to be differences in the amount of progress that particular learners have made. Moreover, the differences are likely to be considerable: they will result from both the "non-deterministic" approach to structure in TBI, and from individual differences between learners. The existence of such differences will make planning the structural content of future tasks very hard, if not impossible. And according to Skehan, tasks should not be unfocused: a range of structures for each task should be specified in advance.

1.3.2. New language and input coverage: The second language context. Skehan (1998: 94) describes the conventional PPP procedure as a "discredited, 
meaning impoverished methodology." I would argue, however, that in terms of providing learners with meaningful samples of the target language, and also in terms of providing them with opportunities for spontaneous language use, modern conventional courses generally leave nothing to be desired. As Swan (2005: 392) observes, they come equipped with a "battery of reading and listening material," which introduces the relevant new structural forms and lexis in a meaningful context. Various communicative activities are also commonplace (e.g., Swan and Walter 1990).

Swan (2005) actually sees the inadequate provision of new language and rich input as one of the major weaknesses of the task-based approach. He claims that TBI is an approach suitable only for input-rich second language teaching contexts, in which the main concern of the learner is to improve the accuracy, fluency and complexity of those forms that already have been acquired. In my opinion, the value of TBI is limited even in this kind of context.

As has been stated earlier, TBI is supposed to activate in learners "the kinds of cognitive processes that arise in communication outside the classroom" (Ellis 2003: 336). Yet it is obvious that in the case of second language learners such cognitive processes will already have been activated by countless communicative encounters which they experience on a daily basis. This does not mean that communicative activities should not be a part of second language instruction: they can, for example, be a source of valuable negative evidence, which may not be provided during interaction outside the classroom. In my view, however, what a second language learner needs as badly as supported communicative activity, and what TBI may not provide, is systematic exposure to structurally complex input and explicit attention to the forms within it.

In theory, a second language learner has unrestricted access to the target input. In practice, though, the types of input that he or she is exposed to may be rather limited. As Wong (2005: 32) observes, "in many ethnic communities such as Chinatown in Chicago, L2 input tends to be limited to conversational language." Classroom instruction, then, should be used as an opportunity to enrich learners' L2 experience with input. Moreover, learners should have their attention focused on those linguistic features that have been shown resistant to purely experiential learning (cf. Harley 1993). Even if explicit instruction concerning those forms will not result in their immediate mastery by the learners, they may still benefit from it by finding it easier to notice and acquire them later (Schmidt 1990, Ellis 2003).

1.3.3. New language and input coverage: the foreign language context. Segalowitz (2003: 401), quoting Ericsson et al (1993) and Ericsson and Charness (1994), states that in order to become an expert skill performer, practice of around 10,000 hours is necessary. He also says that when children reach the 
age of 4 or 5, they will have experienced a comparable amount of communicative activity. By contrast, as Swan (2005) points out, secondary-school EFL pupils are typically given a total of around 600 hours of L2 instruction.

The existence of such time constraints has in Swan's opinion two significant consequences. First, there is the coverage problem: "in the tiny corpus of a year's task-based input, even some basic structures may not occur very often, much core vocabulary is likely to be absent, and many other lexical items will appear only once or twice" (Swan 2005: 393). Second, the activation of natural cognitive processes in the learner cannot be relied upon if the natural conditions that trigger them are not present. To this, it might be added that replicating such conditions in a foreign language context, if it was possible, would be likely to lead to a process that is slow and inefficient. In this connection, let us quote Widdowson (1990: 162), who points out that L1 acquisition itself is not very efficient:

The natural language acquisition process is a long and rather inefficient business. For the child acquiring its mother tongue, knowing a language and internalizing its formal rules is something that happens gradually through trial and error; its competence is the result of a recurrent refocusing as required by increasing performance demands over a period of extensive exposure to and experience of language.

Both Widdowson (1990) and Swan (2005) conclude that classroom-based instruction simply cannot provide the right conditions for such natural learning and, further, that it makes no sense to try it. Widdowson (1990: 162) stresses that the fundamental principle of pedagogy is that various ways are contrived to make the process of learning more efficient than it is in a naturalistic setting. For Swan (2005: 394), compensating for the lack of natural conditions involves "careful selection and prioritizing, proactive syllabus design, and concentrated engagement with a limited range of high priority language elements."

\section{The nature of adult $\mathrm{L} 2$ acquisition}

\subsection{Implicit induction vs. explicit problem solving}

The central principle of task-based instruction is the activation of "acquisitional processes" in the learner (Skehan 2003: 1). These processes are supposed to lead to the development of implicit L2 knowledge, with learners acquiring particular L2 features as they are ready to do so (i.e. as their internal syllabus allows them to). Since implicit induction and the influence of domain-specific, learner-internal factors are also two fundamental characteristics of L1 acquisition, one can describe TBI-induced learning as involving natural language development. 
However, there is reason to believe that for adult L2 learners the meaning of the term "natural" can be very different from the meaning of this term in the case of child learners. For adult learners, acquiring a foreign or a second language naturally might mean acquiring it in the way in which other cognitive skills are acquired, which generally means starting from an explicit declarative representation and accumulating a sufficient number of (partial) entities to perform the skill:

As a learner I have two major problems to overcome - accumulating a large number of partial entities, whether they be lexical items, grammatical rules, or whatever; secondly, finding opportunities to try out combinations of them, in both structured and unstructured situations. Once I have acquired, say, two thousand partial entities, I am better placed to communicate than if I have acquired only a hundred. (Moore 1989, quoted in Ellis 1997: 141-142)

One fundamental cognitive difference between children and adults is that the latter are equipped with a general problem-solving mechanism. This mechanism can deal with abstract formal systems and adults use it to acquire cognitive skills like chess-playing or arithmetic. It seems plausible to assume that this mechanism will also play a central role in the process of the acquisition of a second/foreign language. As Bley-Vroman (1989) points out, this assumption is supported by the fact that adult L2 acquisition shares a number of general characteristics with the process of skill development, and differs in crucial respects from child L1 acquisition. For example, in adult L2 acquisition there is variation in the level of success that learners achieve, variation in the reliability of grammaticality judgements that they can make, and variation in the goals and strategies that they employ. Also, adult learners make use of various forms of instruction and their learning is affected by factors like personality and motivation. These characteristics are not shared by first language acquisition: all normal children invariably achieve perfect success in the task; in the process they do not make use of explicit formal instruction and they are not influenced by affective factors. Progressing in certain predictable stages children develop implicit knowledge of the system. When the system is in place, they can make clear grammaticality judgements.

Any account of adult L2 acquisition will have to deal with these issues. One way in which this can be done (Bley-Vroman 1989) is to assume that L1 acquisition is determined by domain-specific implicit learning processes, and that these processes are replaced in adults by general problem-solving systems:

\begin{tabular}{ll}
\hline Child language development & Adult foreign language learning \\
\hline 1. Universal Grammar & 1. Native language knowledge \\
2. Domain-specific learning procedures & 2. General problem-solving systems \\
\hline
\end{tabular}

(Bley-Vroman 1989: 51) 
Another (Truscott and Sharwood Smith 2004) is to say that in both L1 and L2 acquisition the same processing system is available, but that in the latter two knowledge bases (L1 and L2 knowledge) compete for access to this system.

Even if Truscott and Sharwood Smith are correct, adult learners may still fail to employ language-specific processing: it may be suppressed by the competing general problem-solving mechanism. Felix (1985) claims that even though this general cognitive mechanism is not particularly suitable for language acquisition, it is dominant in adults, who almost invariably use it when dealing with abstract systems.

\subsection{Implicit vs. explicit learning: Empirical research}

There is relatively little empirical research which compares implicit and explicit adult L2 learning. DeKeyser (2003: 321-326) reviews a number of studies which focus narrowly on the implicit/explicit L2 issue either in a laboratory context or in a classroom setting. His general conclusion concerning the former context is that the evidence from it is "overwhelmingly in favour of explicit learning", the only exception being the explicit-inductive condition. ${ }^{5}$ As for classroom studies, the body of literature is very thin, but what evidence there is also favours explicit learning.

DeKeyser (2003) also discusses empirical research into implicit learning in areas other than natural language acquisition, namely artificial grammars, sequence learning and control of complex systems. Some of the studies in these experimental paradigms do make claims that an implicit learning of abstract systems is possible in the case of adults. DeKeyser, however, demonstrates that the claims that have been made can be challenged on a number of grounds. For example, it has been shown that the knowledge attributed to the subjects in some of the experiments can be accounted for completely by assuming that they operated with informal conscious rules and were guided by surface similarities rather than by abstract underlying representations. Also, there are methodological problems with measuring implicit and explicit learning: there appear to be no perfect tests or procedures for measuring these two types of knowledge (but see Ellis 2005). That the measurement issue is of vital importance is demonstrated by the fact that the amount of implicit learning that supposedly takes place in these experiments is rather modest: it is typically 5570 percent, where 50 percent indicates performance at the chance level. This means that even a small problem with the measurement can affect the results significantly.

5. DeKeyser admits, however, that because the studies are of relatively short duration, one can argue that they are biased against implicit learning. 
Given all the problems and controversies mentioned above, DeKeyser (2003: $321)$ comes to the following conclusion: "[a] thorough reading of the literature on implicit learning (...) must leave one very sceptical about the possibility of implicit learning of abstract structure, at least by adults." The only cases in which implicit learning may be effective appear to be those involving "concrete and contiguous elements" (DeKeyser 2003: 319).

Empirical evidence for the implicit/explicit distinction in children and adults comes from language aptitude studies. For example, DeKeyser (2000) shows that language aptitude is a significant predictor of L2 proficiency in the case of older, but not of younger learners. Consequently, he says that the critical period hypothesis should be understood as consisting in children losing the ability to rely exclusively on implicit learning mechanisms in the acquisition of language.

\subsection{Implicit learning, explicit learning and the age factor}

The conclusion I would like to draw from the foregoing discussion is that children and adults generally rely on two different learning mechanisms for language acquisition: implicit and explicit mechanisms respectively. Since both of these mechanisms are natural learning mechanisms I would argue that the term "natural language acquisition" should be interpreted in two different ways, depending on the age of the learners. For child L1 learners, it should be taken to refer to the process in which implicit linguistic knowledge arises out of communication and is driven by a language-specific internal syllabus or mechanism. For adult L2 learners, it should designate the process in which an explicit representation of a linguistic system is developed with the help of a general cognitive mechanism. Accepting this distinction means that when talking about "naturalness" in adult L2 acquisition one should appeal to models of general skill acquisition which include an explicit knowledge component, rather than to models of $\mathrm{L} 1$ acquisition, in which implicit knowledge is developed directly from a communicative use of a language.

\subsection{From the deliberate to the automatic}

The skill acquisition theory that is often invoked in the context of L2 learning is that of John Anderson (e.g., 1982, 2000). In his theory, the process of acquiring a skill takes place in three stages: the cognitive (declarative) stage, the associative (procedural) stage and the autonomous stage.

In the first stage, learners deliberately use their explicit/declarative knowledge to perform a particular skill. That is, they use the factual information they have about a given domain to carry out problem-solving operations. These 
problem-solving operations are domain independent: as Anderson shows, they are applied in numerous cognitive domains and consist in learners consciously searching for correspondences between rules and aspects of the problem at hand. So, for example, a learner of English in the initial stages of the acquisition of the present perfect would first need to decide whether the situational context at hand corresponds to the conditions for the use of the present perfect. This could involve verbally rehearsing all the relevant information. Then, assuming that the conditions are met, the learner would have to consciously apply the rule for the formation of the present perfect, accessing in the long term memory all the relevant verb forms. Johnson (1996: 93) proposes the following formulae to illustrate this process:

IF the goal is to form the present perfect of a verb and the person is 3rd singular THEN form the 3rd singular of 'have'

IF the goal is to form the present perfect of a verb and the appropriate form of 'have' has just been formed

THEN form the past participle of the verb

Applying declarative knowledge in the manner described above is a very time consuming process. In the associative stage, the time involved in performing a skill is drastically reduced. This is possible because the importance of the cognitive component is diminished: the problem-solving mechanism is replaced by a retrieval mechanism which enables learners to retrieve specific solutions to the problems in a given domain. This means that the learner recognizes the applicability of the rule without the need to rehearse it. It also means that the relevant factual knowledge becomes integrated in the production process and no longer needs to be separately searched for in memory. In the case of the present perfect, the following production rule might be involved (cf. Johnson 1996: 94):

IF the goal is to form the present perfect of the verb 'change' and the person is 3rd singular

THEN form 'has changed'

In the final autonomous stage, the deployment of rules becomes totally automatic and cognitive involvement is gradually eliminated. This results in the cognitive system being free to become engaged in other simultaneous tasks. Ultimately, skilled performers may even lose the initial declarative knowledge which was the basis of the first stage.

Adopting a skill-based model of adult L2 acquisition does not force us to assume that all L2 linguistic knowledge necessarily originates as an explicit representation. While stating that forming declarative encodings is a "major 
avenue for the acquisition of procedural knowledge", Anderson and Fincham (1994: 1323) allow for the acquisition of this type of knowledge without the initial declarative representation. Johnson (1996), in his application of Anderson's (1982) model to language learning, also distinguishes two routes which the development of L2 knowledge can follow: the declarative-procedural (DECPRO) route and the direct procedural route (PRO). The latter can occur for example in the case of adult second language learners who do not receive any formal instruction. In a second language context, such "direct procedural encodings" have obvious advantages: they can be executed speedily and they are light on channel capacity. However, as Johnson also points out, there are also disadvantages. First, procedural encodings are inflexible or non-generative: since knowledge is in this case linked to particular productions, it cannot be transferred to other contexts. Second, since procedural knowledge quickly undergoes automatization, it quickly becomes impermeable to change. Thus, if a faulty procedure is automatized, it is very difficult to rectify it and fossilisation may take place.

For Johnson (1996: 100), the inflexibility of procedural knowledge and the risk of fossilisation associated with it, point to the necessity of forming a declarative representation in L2 learning. He makes the following observation: "if we concern ourselves not just with what occurs, but with what should occur, then the only acceptable alternative to DECPRO is not PRO but PRODEC." This means that when adult learners fail to make use of their analytical abilities in the process of L2 acquisition, an attempt should still be made to get them to analyze the knowledge that has been acquired. It seems, then, that the explicit declarative component in L2 learning, even if it is sometimes bypassed by adult learners, cannot be dispensed with if the development of a flexible and generative rule system is to take place.

\subsection{Skill acquisition: Empirical research}

Numerous empirical studies of general skill acquisition have shown that learning curves for skills like text-editing or geometry follow a power function. There is also empirical evidence that L2 grammar learning can proceed in the same way. This has been demonstrated by DeKeyser (1997), who used in his experiment an artificial language he called Autopractan. The subjects in DeKeyser's experiment were first explicitly taught four morphosyntactic rules and 32 vocabulary items in Autopractan. Then they were involved in 8 weeks of production and comprehension practice, and, finally, they were tested on the two skills. The results indicate that learning curves for second language grammar rules follow the same power law that has been shown to apply to other skills. Moreover, as is the case with general cognitive skills, L2 grammar de- 
velopment was demonstrated by DeKeyser to show initial deviation from the power function, and a directional asymmetry of rule application. In more general terms, these findings are evidence that L2 acquisition resembles general skill acquisition not just in its global features, and that the internal characteristics of the two processes are also comparable. ${ }^{6}$

Much more research into the effects of long-term practice and into the relationship between explicit knowledge and spontaneous performance is of course needed. While there are studies (e.g. Macrory and Stone 2000) which demonstrate that learners can only perform part of their explicit L2 knowledge, there is also evidence for a link between explicit rules and the ability to produce spontaneous L2 output. Sorace (1985) examined the metalinguistic knowledge and spontaneous performance of a beginner and an intermediate group of L2 learners of Italian. Three instruments were used: a written test of metalinguistic knowledge and ability, an oral picture description task, and an informal conversation. One of findings of the study that is relevant to the present discussion is that there was a growing interaction between the subjects' metalinguistic knowledge and their L2 proficiency. Sorace (1985: 252) states that this result is hard to explain if "one is not prepared to admit either that formal knowledge can be applied in production, or that it has at least a more central function than limited monitoring".

\section{Teaching through structures}

\subsection{Underlying rules vs performance units}

Proponents of task-based approaches to language teaching generally claim that an ability to communicate can be developed through interaction in the target language and occasional or remedial focus on form. They therefore make the learners responsible for analysing the target language code. Such an analysis is necessary if learners are to develop underlying competence, which, as Widdowson (1990: 137-138) says, "alone can provide the sort of adaptable resource required for actual communication and for further learning." If no analysis is carried out and no underlying competence is built, then learners will not acquire language but "language-like behaviour" - "performance units" not supported by underlying rules.

6. The idea that metalinguistic knowledge is "as open to automatisation as any other domain of knowledge" has recently been expressed by Sharwood Smith (2004: 276). For Sharwood Smith, then, it makes perfect sense to talk about "metagrammatical fluency" and the use of metagrammatical knowledge in spontaneous fluent L2 performance. 
The assumption underlying task-based teaching is that engaging learners in communicative interaction will trigger natural language learning processes leading to acquisition and the development of implicit $\mathrm{L} 2$ knowledge. The main problem with this scenario is that adults may not be able to activate such processes: they operate under severe time constraints, their implicit learning abilities seem rather limited, and they may not be provided by task-based instruction with enough explicit information about the target code to analyse it on their own. If this is indeed the case, then the most likely outcome of task-based instruction for adult learners is a reservoir of performance units with little underlying competence.

\subsection{Criticisms of the structural syllabus}

If one assumes that the only reliable mechanism that adults can resort to in L2 learning is the general problem-solving mechanism, then the only plausible way of implementing instruction, at least in the initial stages, is to facilitate the operation of this mechanism by providing learners with systematic explicit coverage of the target code. This can be achieved with the help of a structural syllabus.

Structural syllabuses are often claimed by SLA specialists (e.g., Long and Crookes, 1992; Robinson, 2001) to artificially isolate linguistic structures and present them separately to the learner. This means that they make the learner responsible for synthesizing these separate bits of linguistic knowledge in "real world performance." The problem with this claim, as Sheen (1994) observes, is that it is simply not true and that it "ignores reality." Sheen (1994: 142) says that

synthetic syllabuses regard the parts as ultimately interdependent. Although a part might be isolated for teaching purposes, it is often initially presented in context, and subsequent practice entails its combination with other parts. Furthermore, such syllabuses assume that a part is eventually integrated into the interlanguage system.

The isolation of structures for presentation and practice in Long and Robinson's view (1998: 16) is supposed to ignore "language learning processes or tacitly assume a discredited behaviourist model." As a matter of fact, behaviourism is not the only model of learning which justifies splitting a complex behaviour into smaller parts and teaching them separately before they are combined in global performance. If we treat language as a complex skill, then we are justified in administering part practice to learners, provided it preserves the essential characteristics of the skill, which in the case of language practice means communicating a message in the target language (Johnson 1996). 
Another argument against structural syllabuses which in my opinion ignores reality is the claim that "sudden categorical acquisition of new forms or rules" is expected of learners (Long and Robinson 1998). As a matter of fact, every L2 teacher realises that, in general, learners do not master new forms or rules instantly. Teachers therefore proceed with the syllabus before complete mastery of a given rule is achieved by learners and expect that further exposure and practice will contribute to further development. It is then at the level of syllabus implementation that the problem of gradual rule development is handled.

Finally, task-based syllabuses are often considered to be superior to the structural ones because of their performance emphasis (e.g., Robinson 2001). The next section shows that the structural syllabus can be the basis of instruction in which performance and communication are not compromised.

\subsection{The communicative structural syllabus}

Describing a syllabus as both communicative and structural need not be a contradiction in terms. First, as Swan (2005:394-95) says, in the early stages of instruction, "a simple grammatical repertoire" is what learners need to fulfil their basic communicative needs. Thus, at this level "a well-planned traditional syllabus is (...), very precisely, an expression of a needs analysis." structural organization of a syllabus does not rule out adopting a communicative methodology in many aspects of its implementation (Widdowson 1990, Johnson 1996). This is because communicative activities need not be restricted to the whole practice component: during part practice one can also use drills which are information-gap exercises. And, of course, in structure-driven instruction, purely communicative whole practice activities also have their place.

The structural syllabus, implemented by both knowledge-oriented and communication-oriented methodology is in line with skill acquisition theory. The traditional PPP format, broken down below into six separate stages, can be used in its implementation:

Stage 1 - Presentation. It is important that in the initial presentation stage learners should be exposed to the relevant structures and vocabulary in a meaningful context which will also be referred to later on in some of the communicative activities. The presentation stage could therefore take the form of schemabuilding exercises (cf. Nunan 2004).

7. At a more advanced level of instruction, the unit of syllabus organization may change. Yalden (1983), Johnson (1996), Marton (2003), Swan (2005) and Pawlak (2006) all argue for a gradual move from structural to communicative principles of organization or for a move from "forms" to "form". 
Stage 2 -Explanation. In this stage the selected grammatical features need to be first isolated and then explained in an explicit way to ensure maximum understanding. If necessary and possible, the teacher can use the learners' native language to achieve this goal.

Stage 3 - Controlled practice. Controlled practice refers to form-focused exercises aimed at developing declarative knowledge. Such exercises could involve filling in blanks, combining sentences, translation, etc. Care should be taken that they are meaningful exercises rather than mechanical drills.

Stage 4-Communicative practice. Learners should now be involved in practising the target behaviour, i.e., conveying meaning, with the help of the newly acquired declarative knowledge. This could be done through communicative drills (Paulston and Bruder 1976, Johnson 1996, DeKeyser 1998).

Stage 5 Communicative production. In this stage learners should be given opportunities to use the structures and expressions they have been working on to achieve some non-linguistic goal. This could be done through focused tasks or problem-solving activities (Widdowson 1990).

If in Stage 5 focused tasks are used, then the framework being described could be labelled as task-supported language teaching (Ellis 2003). I would like to stress, however, that the use of focused tasks (as defined by Ellis) is not crucial to the implementation of the sequence. Situational grammar exercises or problem-solving activities in which learners are to achieve a non-linguistic outcome while being aware of the targeted linguistic feature are perfectly legitimate devices to use in Stage 5. This is in line with Widdowson (1990), for whom avoidance of explicit linguistic priming in the preparation for communicative activities is unnecessary.

Stage 6-Metalinguistic reflection. In this final stage learners' performance in the task is reviewed. Errors made by learners can be discussed and further practice activities administered.

The above sequencing of classroom activities is a fairly traditional way of implementing foreign language instruction and many teachers no doubt follow it in their work to a larger or smaller extent. At the same time it integrates form- and meaning-based activities and conforms with the principles of skill acquisition theory. It appears, then, that Skehan's (1998) criticisms of teachers' persistence in the application of the PPP are unjustified. Also, as Chomsky (1970: 55) said, it is teachers who should ultimately decide on the feasibility of proposals made by researchers and their suitability for particular teaching contexts: 
It is possible - even likely - that principles of psychology and linguistics, and research in these disciplines, may supply insights useful to the language teacher. But this must be demonstrated, and cannot be presumed. It is the language teacher himself who must validate or refute any specific proposal. There is very little in psychology or linguistics that he can accept on faith.

\section{Conclusion}

The central claim of this paper, that natural adult L2 acquisition should be identified with explicit learning, is based on the following premises:

- adults possess a general problem-solving mechanism which they use to acquire cognitive skills

- implicit language-specific acquisitional processes (manifested in L1 acquisition) are either inaccessible to adults or they are suppressed/dominated by the general cognitive mechanism

- the role of domain-independent implicit induction is marginal for learning complex systems by adults

The fact that adults use their problem-solving mechanism in acquiring cognitive skills is well documented by empirical research (e.g. Anderson 2000). While the existence of maturational constraints on L2 learning is still a matter of debate, the evidence for such constraints is substantial, and, as Long (2005) shows, many of the studies whose findings appear to contradict the Critical Period Hypothesis are limited and/or flawed in their design, their methodology or in the conclusions that are drawn. Finally, empirical studies of adult learning have so far failed to provide convincing evidence that adults can acquire implicit abstract knowledge of complex systems (DeKeyser 2003).

While empirical studies of L2 acquisition indicate that linguistic knowledge can successfully be taught in an explicit manner, there remains the problem of converting this knowledge into spontaneous performance. The problem of the gap between knowledge and performance is, of course, not restricted to linguistic skills: that learners have problems turning the former into the latter is something that any teacher or instructor will admit. Thus, when Skehan (1998: 130) says that "learners do not simply learn what teachers teach", he in fact acknowledges that language learning is in this respect like learning most other skills.

The fact that there are problems of transfer does not mean that systematic teaching of explicit knowledge should be abandoned. Instead, we should focus on finding ways in which this can be done most effectively. One possibility that suggests itself is to administer practice strictly along the lines of skill acquisition theory. This generally means using both part and whole practice, making sure that in the case of the former the essential characteristics of the skill are 
preserved. Failing to do so may explain why in so many cases practice does not appear to be effective.

The exact type of treatment (i.e., teaching and practice) that a particular L2 phenomenon receives should also be related to the level of difficulty that it poses. While the notion of difficulty is an individual issue (DeKeyser 2003: 331), there have been attempts to examine the relationship between linguistic difficulty and explicit/implicit knowledge (e.g., Green and Hecht 1992, Ellis 2006). The research indicates, among other things, that not all linguistic phenomena are equally amenable to being presented as exhaustive rules. In my view, however, this does not mean that complex notions should not be tackled explicitly. As Green and Hecht (1992: 180) say: "semantic categories like aspect are probably best presented as explanations rather than rules, with learners' attention drawn to how they operate in longer contexts (...)".

Empirical research is definitely needed to document how explicit teaching followed by practice affects language development over long periods of time. DeKeyser (2007: 1) says that "[p]ractice gets a raw deal in the field of applied linguistics". It is high time to change this state of affairs.

Adam Mickiewicz University <spawel@ifa.amu.edu.pl>

\section{References}

Anderson, John R. (1982). Acquisition of cognitive skill. Psychological Review 89 (4): 369-406.

Anderson, John R. (2000). Learning and Memory. An Integrated Approach (second edition). New York: John Wiley and Sons.

Anderson, John R. and Jon M. Fincham (1994). Acquisition of procedural skills from examples. Journal of Experimental Psychology 20 (6): 1322-1340.

Bley-Vroman, Robert (1989). What is the logical problem of foreign language learning? In Linguistic Perspectives on Second Language Acquisition, Susan M. Gass and Jacquelin Schachter (eds.), 41-68. Cambridge, UK: Cambridge University Press.

Bruton, Anthony (2002). From tasking purposes to purposing tasks. ELT Journal 56 (3): 280-288.

Chomsky, Noam (1970). Linguistic Theory. In Readings in Applied Transformational Grammar, Mark Lester (ed.), 51-60. New York: Holt, Rinehart and Winston, Inc.

DeKeyser, Robert M. (1997). Beyond explicit rule learning: automatizing second language morphosyntax. Studies in Second Language Acquisition 19 (2): 195-221.

DeKeyser, Robert M. (1998). Beyond focus on form: Cognitive perspectives on learning and practising second language grammar. In Focus on Form in Classroom Second Language Acquisition, Catherine J. Doughty and Jessica Williams (eds.), 114-138. Cambridge, UK: Cambridge University Press.

DeKeyser, Robert M. (2000). The robustness of critical period effects in second language acquisition. Studies in Second Language Acquisition 22 (4): 499-533.

DeKeyser, Robert M. (2003). Implicit and explicit learning. In The Handbook of Second Language Acquisition, Catherine J. Doughty and Michael H. Long (eds.), 313-348. Malden, MA and Oxford, UK: Blackwell. 
DeKeyser, Robert M. (2007). Situating the concept of practice. In Practice in a Second Language, Robert M. DeKeyser (ed.), 1-18. Cambridge, UK: Cambridge University Press.

Doughty, Catherine J. and Elizabeth Varela (1998). Communicative Focus on Form. In Focus on Form in Classroom Second Language Acquisition, Catherine J. Doughty and Jessica Williams (eds.), 114-138. Cambridge, UK: Cambridge University Press.

Ellis, Rod (1994). The Study of Second Language Acquisition. Oxford, UK: Oxford University Press.

Ellis, Rod (1997). SLA Research and Language Pedagogy. Oxford, UK: Oxford University Press.

Ellis, Rod (2003). Task-based Language Learning and Teaching. Oxford, UK: Oxford University Press.

Ellis, Rod (2005). Measuring implicit and explicit knowledge of a second language. A psychometric study. Studies in Second Language Acquisition 27 (2): 141-172.

Ellis, Rod (2006). Modelling Learning Difficulty and Second Language Proficiency: The Differential Contributions of Implicit and Explicit Knowledge. Applied Linguistics (27) 3: 431-463.

Ellis, Rod, Helen Basturkmen and Shawn Loewen (2001). Learner uptake in communicative ESL lessons. Language Learning 51 (2): 281-318.

Ericsson, K. Anders, Ralf T. Krampe and Clemens Tesch-R?mer (1993). The role of deliberate practice in the acquisition of expert performance. Psychological Review. 100 (3): 363-406.

Ericsson, K. Anders and Neil Charness (1994). Expert performance: Its structure and acquisition. American Psychologist 49 (8): 709-724.

Felix, Sascha W. (1985). More evidence on competing cognitive systems. Second Language Research 1 (1): 47-72.

Foster, Pauline (1998). A classroom perspective on the negotiation of meaning. Applied Linguistics 19 (1): 1-23.

Gass, Susan and Evangeline Varonis (1985). Task variation and non-native/non-native negotiation of meaning. In Input in Second Language Acquisition, Susan Gass and Carolyn Madden (eds.), 149-162. Rowley, MA: Newbury House.

Green, Peter, S. and Karlheinz Hecht (1992). Implicit and explicit grammar: An empirical study. Applied Linguistics 13 (2): 168-184.

Gregg, Kevin R. (1984). Krashen's Monitor and Occam's Razor. Applied Linguistics 5 (2): 79-100.

Goldschneider, Jennifer M. and Robert M. DeKeyser (2001). Explaining the "natural order of L2 morpheme acquisition" in English: A meta-analysis of multiple determinants. Language Learning 51 (1): 1-50.

Harley, Birgit (1993). Instructional strategies and SLA in early French immersion. Studies in Second language Acquisition 15 (2): 245-259.

Hulstijn, Jan H. (2005). Theoretical and empirical issues in the study of implicit and explicit second-language learning. Studies in Second Language Acquisition 27 (2): 129-140.

Inhelder, Barbel and Jean Piaget (1958). The Growth of Logical Thinking from Childhood to Adolescence. New York: Basic Books.

Johnson, Keith (1996). Language Teaching \& Skill Learning. Oxford, UK and Cambridge, MA: Blackwell

Krashen, Stephen D. and Tracy D. Terrell (1983). The Natural Approach: Language Acquisition in the Classroom. Oxford: Pergamon.

Long, Michael H. (1996). The role of the linguistic environment in second language acquisition. In Handbook of Second Language Acquisition, William C. Ritchie and Tej K. Bhatia (eds.), 413-468. San Diego: Academic Press.

Long, Michael H. (2005). Problems with supposed counter-evidence to the Critical Period Hypothesis. International Review of Applied Linguistics 43 (4): 287-317.

Long, Michael H. and Graham Crookes (1992). Three approaches to task-based syllabus design. TESOL Quarterly 26 (1): 27-56. 
Long, Michael H. and Peter Robinson (1998). Focus on form. Theory, research and practice. In Focus on Form in Classroom Second Language Acquisition, Catherine J. Doughty and Jessica Williams (eds.), 15-41. Cambridge, UK: Cambridge University Press.

Macrory, Gee and Valerie Stone (2000). Pupil progress in the acquisition of the present perfect tense in French: the relationship between knowledge and use. Language Teaching Research 4 (1): 55-82.

Marton, Waldemar (2003). A maximum-efficiency model for the teaching of L2 grammar in a foreign-language, non-intensive context. Paper presented at 34th Poznań Linguistic Meeting.

Moore, Alan (1989). Review of "Second language grammar: learning and teaching" by William E. Rutherford. ELT Journal 43 (2): 155-157.

Norris, John M. and Lourdes Ortega (2000). Effectiveness of L2 instruction: a research synthesis and quantitative meta-analysis. Language Learning 50 (3): 417-528.

Nunan, David (2004). Task-based Language Teaching. Cambridge, UK: Cambridge University Press.

Paulston, Christina and Mary Bruder. (1976). Teaching English as a Second Language: Techniques and Procedures. Cambridge, MA: Winthrop.

Pawlak, Mirosław (2006). The Place of Form-focused Instruction in the Foreign Language Classroom. Kalisz, Poznań: Uniwersytet im. Adama Mickiewicza.

Pica, Teresa (1994). Research on negotiation: What does it reveal about second-language learning, conditions, processes and outcomes? Language Learning 44 (3): 493-527.

Pienemann, Manfred (1985). Learnability and syllabus construction. In Modelling and Assessing Second Language Acquisition, Keneth Hyltenstam and Manfred Pienemann (eds.), 23-75. Clevedon: Multilingual Matters.

Robinson, Peter (2001). Task complexity, cognitive resources, and syllabus design: a triadic framework for examining task influences on SLA. In Cognition and Second Language Instruction, Peter Robinson (ed.), 287-318. Cambridge, UK: Cambridge University Press.

Rosansky, Ellen J. (1976). Methods and morphemes in second language acquisition. Language Learning 26 (2): 409-425.

Schmidt, Richard (1990). The role of consciousness in second language learning. Applied Linguistics 11 (2): 17-46.

Segalowitz, Norman (2003). Automaticity and second languages. In The Handbook of Second Language Acquisition, Catherine J. Doughty and Michael H. Long (eds.), 382-408. Malden, MA and Oxford, UK: Blackwell.

Sharwood Smith, Mike (2004). In two minds about grammar: On the interaction of linguistic and metalinguistic knowledge in performance. Transactions of the Philological Society 102 (2): 255-280.

Sheen, Ron (1994). A critical analysis of the advocacy of the task-based syllabus. TESOL Quarterly 28 (1): 127-151.

Skehan, Peter (1998) A Cognitive Approach to Language Learning. Oxford, UK: Oxford University Press.

Skehan, Peter (2002). A non-marginal role for tasks. English Language Teaching Journal 56 (3): 289-295.

Skehan, Peter (2003). Task-based instruction. Language Teaching 36 (1): 1-14.

Skehan, Peter and Pauline Foster (2001). Cognition and tasks. In Cognition and Second Language Instruction, Peter Robinson (ed.), 183-205. Cambridge, UK: Cambridge University Press.

Sorace, Antonella (1985). Metalinguistic and language use in acquisition-poor environments. Applied Linguistics 6 (3): 239-254.

Spada, Nina and Patsy M. Lightbown (1999). Instruction, first language influence and developmental readiness in second language acquisition. Modern Language Journal 18 (1): 1-22.

Swain, Merrill (1995). Three functions of output in second language learning. In Principle and Practice in Applied Linguistics, Guy Cook and Barbara Seidlhofer (eds.), 125-144. Oxford, UK: Oxford University Press. 
Swan, Michael (2005). Legislation by hypothesis: The case of task-based instruction. Applied Linguistics 26 (3): 376-401.

Swan, Michael and Catherine Walter (1990). The New Cambridge English Course. Cambridge, UK: Cambridge University Press.

Truscott, John and Mike Sharwood Smith (2004). Acquisition by processing: a modular perspective on language development. Bilingualism: Language and Cognition 7 (1): 1-20.

Widdowson, Henry G. (1990). Aspects of Language Teaching. Oxford, UK: Oxford University Press.

Willis, Jane (1996). A Framework for Task-based Learning. Harlow: Longman.

Wong, Wynne, (2005). Input Enhancement: From Theory and Research to the Classroom. New York: McGraw-Hill.

Yalden, Janice (1983). The Communicative Syllabus: Evolution, Design, and Implementation. Oxford, UK: Pergamon Institute of English. 